\title{
Instructions To Authors
}

Ethical and legal prerequisites: Manuscripts handed in for publication dealing with examinations of probands and patients must include the declaration that the trial protocol has been approved by an ethical committee and thus meets the standards of the Declaration of Helsinki (1964). At the same time the proband's informed consent has to be included in the manuscript. Information suitable to reveal the proband's identity is to be avoided.

Planned animal experiments demand consent as well and must meet the requirements of the German laws protecting animals in the version of 1986. A reference to this approval must be included in the manuscript. Articles from outside the FRG have to include a comparable notice. 1. General Remarks - Publishing Laws Please send your manuscript directly to S. KARGER Publishers, attn.: Mrs. Susanne Meister, Lörracher Str. 16 a, D-79115 Freiburg. Contributions are classified as review articles, original papers, ongoing clinical trials, FAX communication, casuistic contributions, clinical pathological conference, letters to the editors, congress reports, clinical information, Wilsede School, book reviews, industrial forum, and reports of Oncological Societies.

Review articles, original papers, ongoing clinical trials, FAX communication and casuistic contributions must be written in English. All other contributions may be handed in optionally in German or English.

The manuscript should be submitted in triplicate, ready for printing. Acceptance of scientific contributions is based on the evaluation by several referees. The author should always keep a copy of the manuscript. The publisher reserves the right to edit the manuscript and decide on the layout.

The manuscript is received with the understanding that it is not under simultaneous consideration for publication elsewhere. It is the author's responsibility to obtain permission to reproduce illustrations, tables etc. from other publishers. Once the manuscript is accepted for publication, all the rights will be retained by the publisher. The publication, or parts of it, may not be translated into other languages, or reproduced by any mechanical or electronic means (including photocopying, recording and microcopying), or stored in a retrieval system without the publisher's written permission. Registered trade names must be marked with the superscript registration symbol ${ }^{\circledR}$. It is the sole responsibility of the author to ensure that this rule is followed properly.

\section{Manuscripts}

The text of the manuscripts should be limited to 10 pages and should be typed in a spacing of Vh lines with adequately wide margins (left and right). They should be consecutively numbered (including front page and reference list). We recommend the following division:

Front page with title and short title in German and English; authors' names, institute name in the native language of the authors.

Summary and Key Words in English and German (translation by the editor is possible). Summaries should be structured in: Background, Material and Methods, Results, Conclusions. 
Summaries should not include any references, tables, figures, references to figures and tables and general statements. Each article should have 3-5 key words.

Text pages should be divided into Introduction, Materials and Methods (optionally Patients and

Methods), Results, Discussion.

Footnotes (with numbers) are placed at the bottom of each page of the text.

Please use abbreviations as economically as possible. Special abbreviations should be written in full when first mentioned followed by the abbreviation in parentheses, e.g. adenosine monophosphate (AMP).

Acknowledgements should be placed directly after the text and before the list of references.

The list of references should include only the publications cited in the text. The references should be numbered according to their order of appearance in the text. In each reference all authors should be denoted, 'et al.' should not be used. It is recommended to quote only articles which have been either published already or accepted for publication. Please avoid passages like 'in preparation' or 'personal communication'.

Quotes from references are inserted into the text with or without the

name of the first author, e.g. [1], or Romberg [1] or Romberg et al.

$[!]$

For references the following examples are compulsory:

Outline of a magazine reference:

Kauffman HF, van der Heide S, Beaumont F, Blok H, de Vries K: Class-specific antibody determination against Aspergillus fumigatus by means of the enzyme-linked immunosorbent assay . III. Comparative study: IgG, IgA, IgM ELISA titers, precipitating antibodies and IgE binding after fractionation of the antigen. Int Arch Allergy Appl Immunol 1986;80:300-306. Outline of a book reference:

Hardy WD Jr, Essex M: FeLV-induced feline acquired immune deficiency syndrome: A model for human AIDS; in Klein E (ed): Acquired Immunodeficiency Syndrome. Prog Allergy. Basel, Karger, 1986, vol 37, pp 353-376.

The number of figures and tables should be limited and aim to illustrate the text. Figures are listed in the text as (fig. 1), tables as (table 1). Figures already mentioned in the text need not be repeated in a table. Accordingly, numbers used in tables need not be repeated in the text. Figures in color may be accepted, provided the author is prepared to defray the costs involved. Original figures should be submitted in triplicate. Do not fasten them with glue or paper clips or punch holes in them. Please state on the back the author's name, the title of the article, the 'top' instruction and the number of the figure.

All figures and tables must include a legend. All legends should be listed together on a separate page. Legends should be kept short and precise and should illustrate the figures and tables exhaustively. The data should not be interpreted in the legend but exclusively in the text. Review articles do not adhere to the framework of original papers. The title page, a summary, key words and a list of references (see above) are, however, compulsory.

Author's address

Please give the author's full address at the bottom of the article.

3. Costs of Reprints

The author will be charged for corrections to the galley proofs entailing expenses in excess of $10 \%$ of the original typesetting costs. The author is entitled to 25 free reprints of his or her article.

(C) 1995 S. Karger GmbH, Freiburg 